\title{
Metamorfosis laboral y reciclaje
}

\author{
Alejandro Mariatti \\ Universidad de la República Oriental del Uruguay (UdelaR)
}

\section{Metamorfosis laboral y reciclaje}

Resumen: Este artículo es producto de una investigación sobre el llamado "mundo del trabajo" y sus transformaciones a nivel mundial en los últimos treinta años, con énfasis en los cambios significativos ocurridos en Uruguay. La investigación fue realizada entre los años 2003 y 2004, como Tesina de graduación de Licenciatura en Trabajo Social de la Universidad de la Republica, Uruguay. El objetivo fue, conocer bibliografica y teoricamente la situación del empleo en Uruguay y de la precarización como forma de sostener la tasa de lucro del Capital. La metodología fue basicamente de análisis teórico. Sin embargo, el autor trabajó tres años como asistente social en el asentamiento al que se hace referencia en este artículo, lo cual permitió tener un conocimiento mas real de la situación que se describe teoricamente. Como conclusiones primarias, se puede decir que un desempleo estructural motor del pauperismo actual - singularizado entre otros por los clasificadores de residuos o "buscadores del cartón"- presenta características que lo hacen funcional con la reducción de costos que lo generó, cerrando entonces un circuito donde el capital vuelve precarias las relaciones laborales y las mantiene en tanto le permiten sostener y aumentar la tasa de lucro.

Palabras clave: trabajo, empleo, cuestión social, reciclaje.

\section{Metamorfose laboral e reciclagem}

Resumo: O presente artigo é produto de uma pesquisa sobre o chamado "mundo do trabalho" e as suas transformações no nível mundial nos últimos trinta anos, com énfase nas mudanças significativas acontecidas no Urugai. A pesquisa foi realizada entre os anos $2003 \mathrm{e}$ 2004 como Trabalho de Conclusão da Licenciatura em Serviço Social na Universidad de la República, Uruguai. O objetivo foi conhecer, numa perspectiva bibliográfica e teórica, a situação do emprego no Uruguai e a precarização como forma de sustentar a taxa de lucro do Capital. A metodología utilizada foi básicamente de análise teórica. Não obstante, o autor trabalhou três anos como assistente social no assentamento referido neste artigo, o que permitiu ter um conhecimento mais real da situação que se descreve de forma teórica. Como conclusões preliminares, pode-se dizer que um desemprego estrutural, motor do pauperismo atual - singularizado dentre outros pelos classificadores de resíduos ou "catadores de papelão" - apresenta caracterísiticas que o tornam funcional para a redução de custos que o gerou, fechando assim um circuito onde o capital transforma em precárias as relações laborais e as preserva na mendida em que permitem sustentar e aumentar a taxa de lucro.

Palavras-chave: trabalho, emprego, questão social, reciclagem.

\section{Labor Metamorphosis and Recycling}

Abstract: This article is the product of a study about the "world of labor" and its transformations at the global level in the past 30 years, with an emphasis on the significant changes underway in Uruguay. The study was conducted in 2003 \& 2004, as a final project in the school of Social Service at the University of the Republic, Uruguay. The purpose was to understand, through a bibliographic and theoretical perspective, the situation of employment in Uruguay and the maintenance of precarious conditions as a form of sustaining the rate of profit of capital. The methodology used was basically that of theoretical analysis. The author worked for three years as a social assistant in a settlement, which allowed her to gain a more realistic understanding of the situation that is described in a theoretical manner. As a preliminary conclusion, it can be said that structural unemployment, the key cause of current poverty - strongly symbolized by the "cardboard pickers" - has characteristics that let it serve to reduce production costs, thus completing a circuit in which capital makes labor relations precarious and maintains them at a level that allows sustaining and increasing the rate of profit. Key words: labor, employment, social question, recycling. 


\section{Introducción}

El artículo que se presenta a continuación surge de reflexiones en relación al complejo (por la profundidad de sus causas), contradictorio (como expresión de relaciones antagónicas entre clases) y heterogéneo (por el caleidoscópico modo de expresión que adquiere según las peculiaridades de cada relación) "problema" de desempleo estructural ${ }^{1}$ que muchos países del "Tercer Mundo" enfrentan, de un modo mas pronunciado, desde mediados de 1970, vinculándose dialécticamente al desarrollo de los países centrales. Este documento no surge de investigaciones empiricas, sino tan solo de un trabajo teórico y se introduce en el debate relacionado con la temática de la "exclusión del mercado laboral y sus consecuencias para las personas que viven de vender su fuerza de trabajo", con la intención de aportar a la reflexión teórica de estos procesos en los que se involucra, entre otros, la intervención del Trabajo Social. A modo de introducción, serán definidas las estrategias de sobrevivencia de personas que habitan una pequeña zona de un barrio de la ciudad de Montevideo, situándolas como objetivación de su momento histórico. Seguidamente serán sintetizadas algunas tendencias generales de la economía planetaria después de la Segunda Guerra Mundial, encontrando particulares expresiones en Uruguay, en diálogo y contrapunto con el desarrollo de las economías centrales. Finalmente se particularizará brevemente la metamorfosis del mundo del trabajo, las nuevas formas que hoy asumen las relaciones de producción y el desempleo en Uruguay, exponiendo, algunas situaciones de pauperismo y trabajo informal vinculadas al reciclaje como expresiones actuales de "la cuestión social", y ésta última, situada como contradicción inherente de la totalidad concreta de la sociedad burguesa, surgida de las necesidades "intestinas" de la permanente valorización del capital.

\section{Objetivos}

Los objetivos de este estudio son realizar un análisis teórico, bibliográfico y abstracto de aquel lugar (asentamiento irregular), descifrando nuevas mediaciones a través de las cuales se define la contradicción entre el capital y el trabajo, y a su vez confrontar con visiones fragmentarias, "epidérmicas", análisis fenoménicos de las problemáticas que mencionamos con anterioridad, fundamentando las codeterminaciones y diálogos que la realidad presenta como totalidad ${ }^{2}$ que solo puede ser definida desde la profundidad de sus causas históricas. Este análisis se contrapone al término "exclusión social" como representación de un "adentro" y de un "afuera" imaginarios. Siendo la realidad una totalidad contradictoria y dialéctica no es posible estar fuera o dentro. El concepto de "exclusión" da cuenta de su orientación conservadora que presupone una sociedad estable, armónica, rígida, ignorando que la sociedad capitalista es una sociedad de lucha de clases atravesada por intereses contradictorios desiguales y combinados. En el transcurso del documento se podrán leer definiciones como "exclusión parcial" o "exclusión del mercado formal de trabajo" lo cual no "excluye" su vinculación con la producción social como totalidad contradictoria y dialéctica. De hecho el siguiente documento presenta una de las formas de inclusión en la producción social de valores como es la situación de los clasificadores de residuos.

\section{El Lugar}

El análisis se realiza observando en perspectiva teórica y bibliográfica el barrio Malvín Norte, en Montevideo, Uruguay, en las cercanías de las calles Isla de Gaspar, Larravide, Hilarión de la Quintana y Boix y Merino, escenario popularmente conocido como "la cantera de los presos". Allí se encuentra un conjunto de casas $^{3}$ en su mayoría de bloque, chapa, cartón y madera, en general espontáneamente construidas y carentes de asesoramiento técnico, asentadas irregularmente y sin saneamiento. Estas alternativas habitacionales son la negación a la "expulsión del campo y la ciudad" expresando su emergencia hacia la periferia urbana. La gente de este lugar generalmente adquiere los recursos para vivir de la mendicidad, de realizar trabajos temporales o simplemente recolectando residuos de personas que viven en otros barrios ${ }^{4}$. De todas estas formas de explotación la que analizaré con mayor profundidad será el trabajo de los "buscadores de cartón", sosteniendo la idea de que el material que algunos recogen contribuye a reducir los costos de algunas industrias papeleras ${ }^{5}$. En relación con la recolección, los medios de producción mas utilizados son carros, generalmente de madera sobre un eje de automóvil desguazado con ruedas de caucho y empujados por un caballo. En estos se viaja fundamentalmente de tarde y de noche (horarios en los que intentan anticipar la recolección municipal). Quienes no tienen un caballo tiran del carro con su propia fuerza. En medio del asentamiento sobre la calle Boix y Merino esquinando la cañada Malvín hay un depósito que compra cartón y papel. Allí se pesan y seleccionan según las características y luego se apilan prensados en fardos. El precio a medidados del año 2003 era de 0,50 pesos uruguayos el kilo de papel coloreado y satinado, 3,50 el cartón y los envases plásticos. (En patrón universal a precios del tipo de cambio del 15 de mayo de 2003: 0,01 y 0,11 dólares americanos o 0,05 y 0,35 Reales, respectivamente, según datos del Banco Central del Uruguay) ${ }^{6}$. El depósito vende esos lotes a alguna 
industria papelera ${ }^{7}$. En la industria se lava, se pica y se crea una pasta uniforme que finalmente se procesa como papel reciclado para venderlo en láminas nuevas. Estas factorías reducen sus costos de materia prima y de este modo pueden alcanzar un precio final que compita en mejores condiciones con otras empresas de su ramo. La exclusión del mercado formal de trabajo de estas personas no impide que de alguna forma participen en la producción social valorizando el capital - único modo que tiene de sobrevivir un sistema fundado en la producción de valor de cambio - más aún, colaboran con su recomposición productiva, que vuelve precarias las relaciones laborales existentes para mantener la tasa de ganancia.

\section{La coyuntura}

En el proceso actual de producción y reproducción del capital, los trabajadores excluidos del empleo en establecimientos físicos fijos y controlados por superiores desde sistemas organizados jerárquicamente encuentran formas de sobrevivencia, ampliándose el universo de constitución y reproducción del trabajo colectivo y, de este modo, los contornos y dimensiones de la subordinación real y formal del trabajo al capital. Ahora que el trabajo puede ser realizado en el centro comunitario, en la casa y en la calle, se cubre de un manto de falsa libertad fuera de la fábrica pero profundamente determinado por el capital y por las exigencias de mercado ${ }^{8}$.

Esta coyuntura se expresa como crisis y busca nuevos mercados para negarla no solo donde colocar los productos sino donde abaratar costos de mano de obra. Este proceso de recomposición mundial de la tasa de lucro repercute en Uruguay país dependiente a través del cierre de fabricas que ya no podían competir con el capital transnacional, de la expulsión del campo de pequeños productores rurales que no pudieron enfrentar la competencia con el latifundio y del aumento de las tasas de interés a nivel internacional, ampliándose la deuda del país y la dependencia financiera y empobrecimiento de la población con una caída del salario ${ }^{9}$ en los últimos 30 años. Las altas tasas de desempleo que en el año 2002 alcanzan un record histórico nacional del 19,8 $\%{ }^{10}$ de la PEA. Estas condiciones estructurales generaron un empobrecimiento de la población cuya expresión fue la imposibilidad del pago de alquileres y la creación de asentamientos irregulares y precarios $^{11}$ como estrategia habitacional. Este empobrecimiento llevó a muchas familias a vivir de la mendicidad o de la recolección urbana, alejó a las personas de los servicios de salud mutual por seguridad social y la salud pública no dio abasto para ésta nueva gran demanda. La clase dirigente necesitó volver precarias las relaciones laborales para valorizar el capital, y esto llevó al extremo las condiciones de vida de algunas personas, demostrando que la ciudadanía ${ }^{12}$ está condicionada por el ciclo económico.

\section{¿Cuál es la llave heurística que ayude a pensar en el diálogo y contrapunto de algunas economías centrales y algunas economías dependientes como la de Uruguay la tarea de los clasificadores de cartón?}

La obra de John Maynard Keynes giraba en torno a la determinación de los niveles de renta nacional y del empleo en las economías industriales. En el período comprendido entre los años 30 al 50, la clase dirigente de los países centrales "pacta" con los trabajadores una salida reformista en la que la victoria de unos podía ser también la victoria de otros (eufemismo reformista que disfraza la dominación). Todo esto sirvió de escenario para el surgimiento del Estado de Bienestar que, salvando las distancias de las particularidades de cada país, fue un denominador común en los países de occidente. ${ }^{13} \mathrm{El} \mathrm{mo-}$ delo económico keynesiano bajó las tasas de interés como forma de estimular la inversión, sin embargo el desempleo no podía esperarla. Fue entonces que se fomentó la política de pleno empleo desde un papel mas activo del Estado a través de la inversión en obra pública.

En síntesis: se consolidó una nueva expresión en la relación entre el capital y el trabajo.

Los partidos socialistas y los movimientos obreros, encajaban perfectamente con el nuevo capitalismo reformado. Un capitalismo reformado que reconociera la importancia de la mano de obra y de las aspiraciones socialdemócratas ya les parecía bien(HOBSBAWM, 1996, p. 275).

El régimen de acumulación que imperó entre las décadas del 40 al 70 en los países centrales, expresó un movimiento de expansión hacia una sociedad de consumo en masa y unas posibilidades laborales que 
fueron absolutamente funcionales con el modo de acumulación de ese momento histórico. La estrategia económica keynesiana tuvo una feliz comunión con el modo de producción "taylorista" 14 y el inicio de una serie de características tales como la homogenización de las condiciones de trabajo creando al obrero especializado del encadenamiento sincronizado; la maximización de la producción desde una racionalización del proceso de trabajo a partir del "reloj", redimensionando el "taylorismo" con el "fordismo" "15 y consolidándose, así, una relación entre la producción (generalización de la cadena de montaje semiautomática) y el consumo en masa ${ }^{16}$.

Hasta ese entonces el trabajador era considerado como un productor máximo y un consumidor mínimo(CASTEL, 1997, p. 338).

[...] el arma secreta de una sociedad opulenta popular, el pleno empleo, no se generalizó hasta los años sesenta, cuando el índice medio de paro en Europa occidental se situó en el $1.5 \%$ (HOBSBAWM, 1999, p. 261).

La esperanza de vida se prolongó 7 años y la producción de alimentos aumentó más de prisa que la población. El problema de los países desarrollados era que producían excedentes de alimentos y no sabían que hacer con ellos. "Acabó por resultar mas barato comprar queso holandés en las Antillas que en Holanda." (HOBSBAWM, 1999, p. 263). La producción mundial de manufacturas se cuadruplicó entre principios de los $50 \mathrm{y}$ principios de los 60. El rendimiento de los cereales por hectárea casi se duplicó entre 1950/52 y 1980/82. Este período de auge económico duró tres décadas pero no bor-

ró la contradicción inherente del capital (crisis cíclicas y estructurales, contradicción entre la socialización de la producción y la apropiación privada del producto). La prosperidad llevó a la disminución del ejército de reserva y a una presión alcista de los salarios, aumentando la inflación y desembocando en crisis. Esta contradicción devino en una tendencia a sustituir fuerza de trabajo por maquinaria, alterando la composición orgánica del capital y por último generando una caída en la tasa de lucro. La ley general de la acumulación capitalista considerada a largo plazo intercaló períodos de crecimiento acelerado seguidos de fases de crecimiento desacelerado; con- vulsiones y estancamientos que derivan en crisis económicas generalizadas llamadas crisis de superproducción y superacumulación.

Las economías de los países industrializados, finalizada la Segunda Guerra Mundial, experimentaron un crecimiento con hegemonía clara de los Estados Unidos consolidada en los años $80^{17}$. Desde los años setenta se dieron sucesivos intentos del capitalismo monopolista por encontrar alternativas a una crisis que se presentó como recesión generalizada de la economía internacional, marcando el fin a un padrón de crecimiento sostenido desde la Segunda Guerra Mundial y por tres décadas. A partir de allí se conformaron reajustes y transformaciones que reestructuraron las economías de los países entre los años 1970 y 1980 . Se consolidó la descentralización, transnacionalización y fragmentación geográfica del proceso de trabajo. Las relaciones laborales se precarizaron consolidándose como estrategia de "salvación" la ya existente sub-proletarización y la expansión sin precedentes del desempleo estructural. Comenzó a incluirse la fuerza femenina en el mercado de trabajo. Se descentralizó la producción pero se acrecentó la centralización y la concentración de la riqueza ${ }^{18}$. Actualmente, 370 firmas controlan el 50\% de los activos financieros ${ }^{19}$.

\section{La raíz profunda de esta crisis} estructural fue el exceso de la capacidad de producción de los países centrales y la lógica destructiva del capital, siguiendo su tendencia de utilización decreciente del valor de uso de las mercaderías.
La diferencia en el PNB per cápita entre los países "desarrollados" y los "subdesarrollados" (es decir entre los países de la OCDE y las "economías pequeñas y medianas") siguió aumentando: el de los primeros era, en promedio, 14.5 veces mayor que el $\mathrm{PNB}$ per cápita de los segundos en 1970, y en 1990 era más de 24 veces mayor (HOBSBAWM, 1999, p. 362).

La raíz profunda de esta crisis estructural fue el exceso de la capacidad de producción de los países centrales y la lógica destructiva del capital, siguiendo su tendencia de utilización decreciente del valor de uso de las mercaderías. A inicios de los años 70 la tasa de lucro presentó una fuerte caída, llevando así al agotamiento del padrón de acumulación taylorista / fordista como resultado de su incapacidad de responder a la retracción del consumo, producto del inicio del desempleo estructural, vía sustitución por trabajo muerto que redujera los costos y de las barreras arancelarias a nivel internacional. Se generó una hipertrofia del sector financiero a partir de la compresión de lucros del sector productivo-comercial, llevando a la fuga de capitales hacia aquel sector y centralizando el capital por medio de fusiones de em- 
presas. Como estrategia para enfrentar la crisis se cuestionó el alcance del Estado de Bienestar poniendo en tela de juicio el déficit fiscal devenido del período keynesiano. La ofensiva burguesa ${ }^{20}$ contra el trabajo, desnudando su naturaleza de clase y con el fin de aumentar la plusvalía, consistió en arremeter contra los derechos históricamente conquistados por los trabajadores a través de privatizaciones, desregulaciones, flexibilizaciones ${ }^{21}$, transnacionalizaciones.

\section{La recomposición productiva del capital}

No son por lo tanto las crisis parciales (del petróleo en 1974, del "fordismo", del Estado de Bienestar, etc), las que desencadenan la crisis general; por el contrario, es la contradicción estructural del capital la que acumulativamente desencadena, en momentos históricos determinados y en condiciones peculiares, las crisis particulares. Tal como sosteníamos en páginas anteriores la economía como totalidad concreta supone un proceso de unidad dialéctica de contrarios definiendo, en el escenario de las relaciones entre clases antagónicas, un proceso de desarrollo global de las fuerzas productivas desigual y combinado ${ }^{22}$.

[...] la dependencia comercial supone una transferencia de excedentes (cuantitativa) vía intercambio desigual y condicionamiento de la estructura productiva (cualitativa) por la adecuación productiva y laboral interna a dicha "nueva" división internacional (OLESKER, 2001a, p. 14).

Ejemplo de esto son las políticas de reducción de salarios para competir, políticas de ajuste, de flexibilización. El desempleo estructural se presenta como gran atractivo para la inversión extranjera de los países centrales en los países dependientes. Dicho desempleo genera no solo condiciones de necesidad sino de atomismo de la clase que vive de vender su fuerza de trabajo, generando una correlación de fuerzas que permite reducir los salarios y precarizar aún más las relaciones laborales. Así como la estabilidad económica (preocupación de los gobiernos que quieren captar inversiones extranjeras) permite calcular con mayor seguridad el crecimiento económico de quien invierte, cierto margen de desempleo garantiza mano de obra barata y sin respuesta organizada contra el capital. La correlación neoclásica entre inflación decreciente y desempleo creciente, llamada Curva de Philips: para restaurar el equilibrio macroeconómico de los precios es preciso el desempleo. De éste modo se consolida el modelo de recomposición productiva del capital como estrategia de salida a la crisis recesiva de los setenta, mejorando tecnológicamente en los países centrales (plusvalía relativa) y deteriorando las relaciones laborales en los países dependientes (plusvalía absoluta) $)^{23}$.

\begin{abstract}
Primero, la reestructuración de actividades productivas a escala mundial, trasladando a la periferia aquellas industrias que originan menores utilidades, de modo que se aprovechen de una fuerza de trabajo mucho mas barata en nuestros países subdesarrollados (para mi dependientes). Segundo, el envío de un volumen creciente de recursos financieros al Tercer mundo; Tercero, la promoción de políticas de apertura de corte neoliberal; Cuarto, la práctica de un proteccionismo agudo en los países dominantes [...] (ASTORI, 1983, p. 16)
\end{abstract}

\section{Las raíces en nuestro país}

En nuestro país la crisis económica social y política se consolidó una vez que algunas condiciones externas (Segunda Guerra Mundial y Guerra de Corea) dejaron de ser favorables para la exportación de materias primas, y su estancamiento agudizó las contradicciones internas. Décadas anteriores había sido enfrentada con una incipiente industrialización estatal sustitutiva de las importaciones, pero no pudo sostenerse $^{24}$. El impulso industrial perdió dinamismo y competitividad. El modelo agro exportador se estancó desde 1930 y debió soportar la inflación interna. El modelo industrial, que necesitaba insumos fundamentales como el petróleo y dependía de un mercado interno muy pequeño, no pudo enfrentar el "cuello de botella" económico ${ }^{25}$, ni la presión política del partido de oposición hacia 1955. La crisis que pone fin a dicho impulso constituyó una manifestación más en la evolución de las economías dependientes. Se consolida así una dependencia tecnológica y financiera que acompañará el movimiento de la economía nacional hasta entrado el siglo 21. La subordinación internacional tanto de los mercados como de los préstamos, dejaron entrever el "contrapunto" del desarrollo desigual y combinado a que se hacía referencia en páginas anteriores. Se conforma así el modelo de reajuste autoritario tendiente a concentrar la riqueza y dar mayor poder político al conglomerado empresarial. El modelo neo liberal fue adaptado por la burguesía vernácula en el Plan Nacional de Desarrollo diseñado por la Oficina de Planeamiento y Presupuesto en el período comprendido entre los años 1973-77. Este programa ultraliberal, con el Ingeniero Végh Villegas como Ministro de Economía, en el que el libre mercado apareció como solución a dicha crisis, desata su batalla contra los costos del Estado. Dicho proceso comenzó a "expresarse" con el "congelamiento" de los salarios el 27 de junio de 1968, acompañado de una devaluación que aumentaba el poder de compra de 
los exportadores, significando una rebaja salarial del $15 \%$ en un solo año (OLESKER, 2001a, p. 34). Esta tendencia se profundizaría en los años siguientes ${ }^{26}$ con una apertura irrestricta al exterior, creación de la ley de inversiones extranjeras, libre circulación de activos financieros, disminución progresiva de restricciones a las importaciones y liberalización de la tasa de interés y de las actividades bancarias y financieras. Estas fueron las características más sobresalientes de un modelo iniciado en octubre de 1978, con claras intenciones neoliberales y monetaristas.

Un tipo de cambio fijado no en función de las necesidades de la producción sino de los requerimientos del modelo en materia de control de la inflación y absorción de recursos financieros provenientes del exterior. Provocando una extranjerización de la economía uruguaya: de 22 bancos privados 20 son extranjeros agregándole 17 casas bancarias extranjeras (ASTORI, 1983, p. 16-17).

Hacia 1979 el Estado se retira - gradual pero definitivamente - de la participación en la fijación de precios. "[...] durante 1982, se generan pérdidas de reserva internacionales cercanas a los 600 millones de dólares en ese mismo año, un déficit fiscal que llego a niveles nunca conocidos" (ASTORI, 1983, p. 18). Se alcanzó de este modo una alta dependencia del ingreso de capitales externos. Desde 1990 se inició una estrategia de reducción de la inflación basada en el "ancla cambiaria". Se fijó un tipo de cambio por debajo de la evolución de los costos internos, que llevó a una reducción del precio de los bienes importados. Esto presionó a la baja los precios de los productos nacionales, complementándose con una apertura irrestricta hacia el mercado mundial. Uno de los resultados fue la pérdida de 18.000 puestos de trabajo en la industria textil (OLESKER, 2001a, p. 32). La administración del presidente Luis Alberto Lacalle en el quinquenio 90-95, se inició con un fuerte ajuste fiscal sobre la base de un shock tributario que implicó un mayor gravamen al consumo y la reimplantación del llamado "Impuesto a los sueldos". En este período el Estado se retira de la negociación colectiva y se consolida la desregulación del mercado labora ${ }^{27}$. En la segunda administración del presidente Julio María Sanguinetti se afianzan las medidas de ajuste con un aumento del Impuesto al valor agregado y un aumento del "Impuesto a los sueldos". Éste último alcanzó niveles del orden del 6\%. En este gobierno, además, se crearon los fondos de ahorro previsional conocidos como "AFAP" ${ }^{28}$ como sistema de capitalización individual, "liberalizando" también la seguridad social, ahora en manos de la banca internacional.

De este modo se ve como el desarrollo de las economías centrales condicionó la estructura productiva de las economías dependientes, preparando el escenario para la aparición de trabajadores precarizados (clasificadores) y desempleo estructural, funcional con la ineluctable reducción de costos del capitalismo en su fase superior.

A continuación, se propone una interpretación de la metamorfosis que sobrevino a partir de los años 70 como determinante en la vida de algunas personas, obligándolos a trabajar como clasificadores de residuos.

\section{La metamorfosis del mundo del trabajo}

La crisis es anticipada con astucia por el capital ${ }^{29}$ propiciando las condiciones para la metamorfosis del mundo del trabajo ${ }^{30}$ hacia un modelo "flexible" llamado toyotista ${ }^{31}$ con una tendencia hacia una economía neoliberal. Al respecto dice Meleneu Netto (1996, p. 90):

\section{[...] la abundancia de mano de obra permanece como un factor importante para la colocación de inversiones. Obviamente este factor aislado puede ser insuficiente, mas la búsqueda de "campos vírgenes" hace parte de la estrategia del capital globalizado.}

La necesidad de reducir costos motivó entre otras características: la sustitución de trabajo vivo por maquinaria reorganizando los procesos de producción; la división de mercados a nivel mundial; el aumento de la tasa de desempleo y la marginación en países dependientes; la división global del trabajo (desterritorialización del trabajo ${ }^{32}$ ); la presencia de capital volátil; el cierre de plantas industriales y la reorganización financiera y tecnológica. Algunas de las enormes consecuencias que tuvo para el mundo del trabajo fueron: la creciente reducción del proletariado fabril estable; el incremento del "nuevo proletariado", creación de un sub-proletariado fabril y de servicio (ellos son los trabajadores tercerizados, subcontratados, part-time, tomados generalmente por inmigrantes en Europa, aunque hoy también alcanza a los trabajadores especializados); el aumento significativo del trabajo femenino, según Antunes (2000), alcanzó a mas del $40 \%$ de la fuerza de trabajo en los países centrales); la exclusión de los jóvenes y adultos del mercado de trabajo; la inclusión precoz y criminal de los niños; la expansión del trabajo social combinado, donde los trabajadores de diversas partes del mundo participan del proceso de producción y de servicios ${ }^{33}$. Por tanto la clase trabajadora se fragmentó, heterogeneizó y complejizó. Se creó, por un lado, una escala minoritaria de trabajadores especializados, polivalentes y multifuncionales y, por otro, se consolidó una gran masa de trabajadores 
descalificados, viviendo y sufriendo el desempleo estructural, esperando las necesidades del mercado para ser empleados. Ellos son los trabajadores asalariados de la "economía informal", empleados parcial y/o zafralmente.

Una de las formas que adquiere dicha tendencia en el asentamiento irregular de Malvín Norte es la de juntar cartón para luego venderlo a los depósitos que hacen negocio con la industria papelera que, desde éstas relaciones laborales informales y precarias, amplía su margen de ganancia a partir de la plusvalía absoluta y relativa a la que se hacía referencia con anterioridad. En relación al producto final, la anterior concepción de "cosas duraderas", es suplantada por la falacia de la "calidad total" ${ }^{34}$, con artículos de una vida útil menor, que ofrecen mayores servicios tecnológicos. Este aumento de la producción en artículos menos perdurables además de ampliar las ventas genera grandes cantidades de sobre-empaquetado de nylon y cartón, que siendo un problema ambiental es, al mismo tiempo, una nueva forma de valorización de capital a partir del trabajo de los clasificadores. En la fase de intensificación de "la tasa de utilización decreciente del valor de uso de las mercancías" ${ }^{35}$, la calidad total como expresión fenoménica ${ }^{36}$ se vuelve un mecanismo para la reproducción ampliada de valorización. Toneladas de materiales descartables son producidos para ser consumidos y desperdiciados. Los "buscadores del cartón" forman parte de este proceso recogiendo y clasificando los desechos de otros individuos.

La especificidad de la industria del reciclaje consiste en transformar las secuelas del proceso de destrucción ambiental en un nuevo objeto de producción mercantil, estructurando sus procesos productivos a través de la adopción de nuevas tecnologías, del uso de materiales reciclables y de la organización de una determinada forma de cooperación entre el trabajo que comienza en la calle y continúa en la fábrica (MOTA, 2002, p. 71).

De este modo la empresa moderna se apropia de las contradicciones generadas por la producción "destructiva" de la naturaleza, articulando mecanismos internos y externos a la producción. Internos: ciclo del reciclaje a través del proceso de trabajo que se realiza en cada fábrica; externos: organización de un mercado de clasificadores, contando con la voluntad pública. Este análisis toma en cuenta la centralidad del trabajo en el universo de una sociedad productora de mercancías ${ }^{37}$ cumpliendo una función decisiva en la creación de valores de cambio. Esta función decisiva pone en evidencia la importancia que adquiere la reducción del tiempo físico y la ampliación del trabajo manual directo e intelectual. ¿Cómo se explica que exista trabajo infantil en una sociedad que no necesita el trabajo?, solo si pensamos que lo que necesita el capital, además del trabajo para valorizarse, es la reducción cada vez mas "brutalizante" del costo de ese trabajo. Por esta razón se flexibilizan las relaciones laborales, utilizando mano de obra informal ${ }^{38}$, y quebrando las organizaciones sindicales: "El capital no puede eliminar el trabajo vivo del proceso de creación de valores, él debe aumentar la utilización y la productividad del trabajo de modo de intensificar las formas de extracción del sobretrabajo en tiempo cada vez mas reducido" (ANTUNES, 2000, p. 71).

\section{Consideraciones finales: centralización y crecimiento}

Como había sido expresado al inicio, la conformación de los asentamientos irregulares en Uruguay tiene una relación directa con la recomposición sectorial de la producción. Analizando este movimiento y sus consecuencias en la tasa de desempleo se percibe claramente "una caída de la participación de los sectores del agro y la industria en la generación de riqueza, en el período comprendido entre los años 89 y 99 , desde una orden del $38 \%$ del total a poco mas del 22,5\%" (OLESKER, 2001a, p. 41). El trigo como ejemplo, cayó en cantidad de establecimientos desde 1970. Pasó de contar con 12.310 establecimientos a 3.879 en 1986 , y menos de la mitad de esta última cifra en la actualidad ${ }^{39}$. Es decir que el número de productores disminuyó selectivamente con un grado de creciente transnacionalización. La desaparición de productores pequeños fue la constante. Quizá muchos vinieran a la ciudad en busca de trabajo quedando anclados en los cinturones de la misma "buscando cartón". Por otro lado la industria manufacturera, "perdió 65.669 puestos de trabajo entre 1990 y 1998, reduciendo un 39\% su capacidad de contratación y perdiendo 80 millones de horas trabajadas en 8 años" (OLESKER, 2001a, p. 54). Los trabajadores precarios representan un universo muy importante de activos, casi 300.000 personas (OLESKER, 2001a, p. 78). Su representación política es escasa y sus organizaciones sindicales son débiles. Se ubican en los tramos de las empresas más pequeñas (incluyendo las tercerizaciones y otras nuevas formas de contratación), tienen una alta rotación laboral, bajo nivel de instrucción, reciben ingresos muy bajos y pertenecen a hogares pobres. Sin embargo hay un sector que trabaja en peores condiciones: los excluidos del mercado formal de trabajo.

Ellos son desocupados parciales, trabajadores rurales, trabajadores del sector limpieza, seguridad, zafrales y temporarios. Entre ellos se encuentran los clasificadores $^{40}$ que incluyen a los buscadores de cartón. Sus organizaciones sindicales son inexistentes 
salvo algunas excepciones (Unión de Trabajadores Desocupados [U.T.D.], Unión de Clasificadores de Residuos Urbanos Sólidos [U.C.R.U.S.]), los salarios son insuficientes, la pérdida de derechos laborales es un hecho y provienen de los hogares mas pobres (OLESKER, 2001a, p. 77-81).

Para finalizar me apoyo en las tesis de Olesker (2001a, p. 90) y Lukacs (apud LESSA, 1981, p. 562), respectivamente:

Para que la economía, sustentada en este modelo liberal, dependiente, concentrador y excluyente, crezca, requiere de una dosis de desempleo que es funcional al crecimiento, es decir es parte de su éxito.

Esto porque al mismo tiempo en que el desarrollo tecnológico puede provocar directamente un crecimiento de la capacidad humana, puede también en este proceso sacrificar los individuos (inclusive hasta clases enteras).

A través del camino recorrido, se ha tratado de exponer algunas de las particularidades por medio de las cuales se presenta la "cuestión social"41, definiendo teóricamente mediaciones útiles para pensar la síntesis actual e intentar iluminar la temática trabajada.

\section{Referencias}

ASTORI, D. Los resultados económicos del proceso. Revista Universitaria Diálogo. Montevideo Uruguay, p. 16-17, jun. 1983.

ANTUNES, R. Adeus ao trabalho? Ensaio sobre as metamorfoses e a centralidade do mundo do trabalho. São Paulo: Cortez, 1995.

2000.

El trabajo y los sentidos. GET. Montevideo, oct.

BARBER. W. J. Historia del pensamiento económico. Madrid: Ed Alianza, 1974.

BENTURA, J. P. Los debates actuales en Trabajo Socialy su impacto a nivel regional. Segregación territorial. Seminario Taller. CSIC-DTS-FCS-REGIONALNORTEUniversidad de la República, 2003.

BODEMER, K.; CORAGGIO, J. L.; ZICARDI, A.; URB-AL. 5to Programa de Politicas Sociales Urbanas. IMMComisión de las Comunidades Europeas, 1999

CAETANO, G.; ALFARO, M. Historia del Uruguay contemporáneo. Materiales para el debate. F.C.U./ Instituto de Ciencia Política, Montevideo, 1995.
CASTEL, R. Las metamorfosis de la cuestión social. Una crónica del salariado. Editorial Buenos Aires Paidós, 1997.

CENSO DE CLASIFICADORES. Organización San Vicente Obra Padre Cacho, Intendencia Municipal de Montevideo, ago. 2002

COUTINHO, C. N. Notas sobre cidadania e modernidade. Praia Vermelha, São Paulo, ano, n. 1, p. 145-165, 1997.

HOBSBAWM, E. Historia del siglo XX, 1914-1991. Barcelona: Grijalbo Mondadori, S.A., 1996.

Historia del siglo XX, 1914-1991". Barcelona:

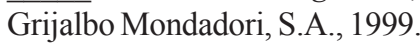

IAMAMOTO, M. Servicio Social y división del trabajo. Un análisis crítico de sus fundamentos. São Paulo: Cortez, 1997. (Biblioteca Latinoamericana de Servicio Social, n. 2).

KOSIK, K. Dialéctica de lo concreto. México: Grijalbo, 1968.

LENIN, V. I. El imperialismo, fase superior del capitalismo. Moscú: Editorial Progreso, 1945.

LESSA, S. La ontología de Lukács. Maceió: Edufal, 1997.

LUKÁCS, G. Ontologia Dell'Essere sociale. Roma: Editorial Riunite, 1981. v. 1 e 2.

MANDEL, E. La formación del pensamiento económico de Marx. España: Editorial Siglo XXI, 1974.

MARX, K.; ENGELS, F. El manifiesto comunista. España: Editorial Edicomunicación, 1999.

MÉTZÁROS, I. Beyond Capital (Towards a Theory of Transición). London: Merlin Press, 1995.

MOTA, A. E. Entre a rua e a fábrica: reciclagem e trabalho precário. Temporalis, ABEPSS, Brasília, ano 3, n. 6, p. 9-22, 2002.

A nova fábrica de consensos: ensaios sobre a reestruturaçao empresarial o trabalho e as demandas ao Servico Social. São Paulo: Cortez, 1998.

OLESKER, D. América Latina: Su potencialidad trasformadora en el mundo de hoy. Uruguay: Ediciones de la Fundación Arismendy, 2003. $\overline{2001 a}$. Crecimiento y exclusión. Uruguay: Editorial Trilce, 
El gobierno antepone la rentabilidad al trabajo. Diario La República. Editorial del día 16 de mayo de 2001. Uruguay, 2001b.

PASTORINI, A. A categoría questão social. Sao Paulo: Cortez, 2004.

PAULO NETTO. J. Capitalismo monopolista e Serviço Social. São Paulo: Cortez, 1992.

REVISTA MONTEVIDEANOS. Intendencia Municipal de Montevideo, n. 2, set. 1999.

SARACHU, G. El trabajo en cuestión: Algunos desafíos para las intervenciones y estudios en el mundo de trabajo en la actualidad. GET. Uruguay, 2001.

\section{Notas}

1 Seconsolidó un desempleo estructural con tendencia creciente de un orden del $10 \%$ de la población económicamente activa (PEA) y un subempleo y precariedad estructural del orden del 25\% delaPEA"(OLESKER, 2001a,p. 84)

2 "Elcapital es un producto colectivo; no puedeponerse enmarcha sinopor la actividad común de muchos miembros de la sociedad y, en último término, sólo por la actividad común de todos los miembros delasociedad"(MARX;ENGELS, 1999,p.114)

3 "De acuerdo a un censo realizado por la ONG Centro de Participación Popular, en cada uno de los dos mayores asentamientos, en Larravide e Isla de Gaspar y en Boix y Merino, viven mas de 1.000 personas, mientras que la cifra es algo menor en Aquiles Lanza. En total la cifra ronda las 4.000 personas" (REVISTA MONTEVIDEANOS, 1999, p. 9).

4 "El clasificador es un trabajador informal que recupera, de los residuos sólidos domiciliarios o comerciales, material destinado al autoconsumo, trueque o venta. Usualmente el clasificador realiza su trabajo con el carro, al que llena de basuraútil e inútil. En su vivienda en el asentamiento realiza el descarte o achique" (REVISTAMONTEVIDEANOS, 1999,p.9).

5 "El asentamiento es el espacio ideal para la reproducción de esta nueva fuerza de trabajo, ya que la misma se logra con costos muy inferiores a los exigidos en la ciudad consolidada, donde reproducir la fuerza de trabajo implica ingresos que permiten el pago de alquiler, de impuestos, agua, luz, etcétera" (BENTURA, 2003, p. 27).

6 Ver:: <www.bcu.gub.uy/autoriza/opinme/oicot/50503.txt.>.

7 Entrevista realizada a Carlos, encargado de la empresa SURNOL S.A. el $1^{\circ}$ de noviembre de 2004. surnol@adinet.com.uy
$8 \operatorname{Ver} \operatorname{Mota}(1998)$

9 Cuadro de participación de las Remuneraciones en el PIB (a precios de mercado). Entre 1970y 1998 el salario real cayo de representarel40.1\%delPBIal25.1\%(OLESKER,2003,p.55-57).

10 Total País Urbano TASADEDESEMPLEO trimestre: Julio/ Septiembre/02: 19\%;Agosto/Octubre/02: 19.2\%; Septiembre /Noviembre/02: 19.8\%.In:<www.ine.gub.uy>

11 “[...] según el último Censo existen 400 asentamientos habitados por 30.000 familias, de cuyos integrantes $33.5 \%$ son menores de 10 años y continua creciendo" (BENTURA, 2003,p. 26).

12 "Ciudadanía es la capacidad conquistada por algunos individuos, o en el caso de una democracia efectiva por todos los individuos, de esa apropiación de los bienes socialmente creados" "Ciudadanía como resultado de una luchapermanente..”.(COUTINHO, 1997,p. 146-165).

13 “... las alteraciones sociopolíticas del capitalismo monopolista, sin configurar un abanico infinito, comportan matices que van de un límite a otro - del Welfare State al fascismo"(PAULONETTO, 1992,p. 17).

14 "Taylor enuncia con un cinismo brutal el objetivo de la sociedad americana: desarrollar al máximo en el trabajador las actitudes de las máquinas y la automatización..., Antonio Gramsci”(SARACHU,2001,p.302)

15 "Se llamo fordismo a la articulación de la producción en masa con el consumo masivo, dijo Henry Ford: la fijación del salario de la jornada de ocho horas en cinco dólares fue uno de los mayores ahorros que haya hechojamás, pero, al llevarla a seis dólares, logréun ahorro aunmás alto"(CASTEL, 1997,p.338).

16 “En 1975 los Siete Grandes del capitalismo por sí solos (Canadá, Estados Unidos, Japón, Francia, Alemania Federal, Italia y Gran Bretaña) poseían las tres cuartas partes de los automóviles del planeta y una proporción casi idéntica de los teléfonos"(HOBSBAWM, 1999, p. 272).

17 Comparando las cifras del año 2000 con las de 1980, observamos que el PIB en EEUU creció un 93\%, la inversión global $180 \%$, la inversión de las empresas cerca de $200 \%$ y en equipo y software $325 \%$. "...Las ganancias globales de las empresas de EEUU, desde 1991 al 1999 se han incrementado más del doble pasando de 430 mil millones a 880 milmillones de dólares”(OLESKER, 2003, p. 55-57).

18 "Dice Ernest Mandel: ...el capitalismo industrial no sobrevivirá a un encierro hermético de capitales y mercaderías en pequeños estados nacionales, así como no hubiera podido desarrollarse en los condados de la Edad Media" (SARACHU, 2001,p. 11). 
19 Ibid.

20 El retorno del paradigma neo liberal, incorporado en la administración de Ronald Reagan en EEUU y la dama de hierro Margaret Thatcher en Inglaterra en la década del ochenta.

21 "Al mismo tiempo, con la Ley 16.713 se habilitan las contrataciones de trabajadores como empresas unipersonales, con lo cual pierden derechos sociales y laborales y quedan expuestos a su “suerte de mercado"(OLESKER, 2001b).

22 "Desigual, porque el ritmo de crecimiento de las diferentes zonas del mundo está determinado por la brecha creciente del desarrollo entre países centrales y países dependientes; Combinado, pues el mayor desarrollo de unos se sustenta en el menor desarrollo de los otros y de esa articulación surge el marconecesario para sostener laacumulación mundial liderada por los países centrales"(OLESKER, 2001a,p. 14).

23 "El coste del trabajo no puede ser en ningún caso inferior al coste de mantener vivos a los seres humanos al nivel mínimo considerado aceptable en su sociedad, o de hecho, a cualquier nivel. Cuanto más avanzada es la tecnología, más caro resulta el componente humano de la producción comparado con el mecánico"(HOBSBAWM, 1999,p. 272,p.414).

24 "La larga crisis económica que se inauguró en los años treinta con el estancamiento del sector agropecuario, prosiguió luego con el estancamiento de la industria hacia mediados de los cincuenta, y generó profundos desequilibrios de todo tipo en el decenio de los sesenta"(ASTORI, 1983,p. 15).

25 "Las reservas de oro y divisas acumuladas durante la guerra, que en 1946 ascendía a 293.1 millones de dólares, en 1956 estaban situadas en 147.0 millones"(CAETANO;ALFARO, 1995,p. 178).

26 "En el año 1984 el salario real había llegado al 35.4\% del que existía en 1957 oal $41.55 \%$ del salario real de 1971"."Mientras que en $196837.5 \%$ de cada 100 pesos que se generaba en el país iban para los asalariados, en 1981 tan solo 23 de cada 100 les correspondíaa laclase trabajadora"(OLESKER, 2001a,p.34).

27 Ya desde 1982 a través de la ley 15.328 se estableció que el régimen general de convenios solo podían ser celebrados por empresa (no por actividad, ni nacionales).

28 "Se desregulo otra parte del funcionamiento laboral con la ley 16.713 conocida como ley de AFAP que posibilitó la transformación de salariados en empresas unipersonales lo que significo una perdida de derechos laborales y mayor inestabilidad laboral"'(OLESKER, 2001a,p. 86).

29 "Las compañías transnacionales (conocidas por multilaterales), la nueva división del trabajo y el surgimiento de actividades offshore (extraterritoriales (paraísos fiscales)".
“Gran parte de lo que las estadísticas reflejan como importaciones o exportaciones es en realidad comercio interno dentro de un entidad transnacional como la General Motors, que opera en cuarenta países"(HOBSBAWM, 1999, p. 280281).

30 "Es necesario calificar: crisis de la sociedad del trabajo abstracto entendida como reducción del trabajo vivo y ampliación del trabajo muerto y no una crisis del trabajo concreto en cuanto elemento estructurante del intercambio social entre los hombres y lanaturaleza"(PASTORINI, 2004,p. 24).

31 "Palabras de Satochi Kamata de la Toyota Motor Company: "si el 33\% de los movimientos desperdiciados son eliminados, en tres trabajadores, uno de ellos se torna innecesario" (ANTUNES, 2000, p. 12-13).

32 "La marca Volkwagen instaló fábricas de automóviles en Argentina, Brasil (tres fábricas), Canadá, Ecuador, Egipto, México, Nigeria, Perú, Sudáfrica y Yugoslavia, sobre todo a mediados de los años sesenta. [...] Así uno de los primeros centros francos de producción industrial, Manaos, en las profundidades de la selva amazónica, fabricaba productos textiles, juguetes, artículos de papel y electrónicos y relojes digitales para compañias estadounidenses, holandesas y japonesas"(HOBSBAWM, 1999, p. 283).

33 Ya en 1916 Lenin hablaba de la llamada combinación: “...la reunión en una sola empresa de distintas ramas de la industria que o bien representan fases sucesivas de la transformación de una materia prima, o bien son ramas de las que unas desempeñan un papel auxiliar con relación a otras" (LENIN, 1945, p 18-19).

34 "...la falacia de la calidad total, en la empresa enxuta de la era de la reestructuración productiva: cuanto mayor calidad total deben tener los productos, menor debe ser su tiempo de duración. La necesidad imperiosa de reducir el tiempo de vida útil de los productos, buscando aumentar la velocidad del circuito productivo"(ANTUNES, 2000, p. 8-9).

35 Ídem. Se refiere a lo dicho por Métzáros (1995).

36 "Si la apariencia fenoménica y la esencia de las cosas coincidieran totalmente, la ciencia y la filosofía serian superfluas"(KOSIK, 1968, p. 55).

37 CitandoaMarx (MANDEL, 1970, p. 90): “[...] si senecesitase un día de trabajo para mantener vivo a un obrero durante un día, el capital no podría existir, pues el día de trabajo se cambiaría por su propio producto, y el capital no podría valorizarse como capital y, por consiguiente, no podría subsistir [...]".

38 "La acumulación genera un excedente de mano de obra, pero a la vez precisa de él para continuar la acumulación. Por ello decimos que la reserva de mano de obra es causa y condición de la acumulación capitalista."(OLESKER, 2001a,p. 20). 
39 En relación al agro y el desarrollo del modelo consolidado a partir de los años 70, en casi todas las producciones del sector se verificaron procesos de liberalización y apertura, lo que sumado al "ancla cambiaria" provocaron una perdida de competitividad que al mismo tiempo concentró la riqueza en los sectores mas dinámicos (este modelo puede ser explicado en parte por la participación de la gran empresa latifundista en el poder dictatorial que dio el golpe de Estado de 1973) (OLESKER, 2001a,p.47).

40 Ver Censo de Clasificadores (2002): "5.312 clasificadores censados; $52 \%$ más clasificadores que el censo voluntario de 1990.; 50\% ingresó durante los últimos seis años; Año 2000 de mayor ingreso (551 casos); 1 de cada 2 clasificadores tiene entre 18 y 39 años"

41 "Entendemos que las manifestación concretas e inmediatas de la "cuestión social" tienen como contra-cara la ley general de acumulación capitalista desarrollada por Marx en El Capital. O sea, las principales manifestaciones de la "cuestión social" - pauperismo, exclusión, desigualdades sociales - son determinaciones de las contradicciones inherentes al sistema capitalista [...]"'(PASTORINI, 2004,p. 97).

\section{Alejandro Mariatti}

Licenciado en Trabajo Social y Docente de la Facultad de Ciencias Sociales de la Universidad de la República Oriental del Uruguay (UdelaR)

\section{UdelaR}

Facultad de Ciencias Sociales

Constituyente 1502 -

C.P.: 11.200

http://www.fcs.edu.uy/

Montevideo - Uruguay 